\title{
Fixed dentulous appliance for maxillary edentate pediatric ridge: A case report
}

\author{
Vinita Goyel $^{1 *}$, Ivin Wilson ${ }^{2}$, Aman Jain ${ }^{3}$, Shivani Mathur ${ }^{4}$, Radhika Chopra $^{5}$, Vinod Sachdev ${ }^{6}$ \\ ${ }^{1,3} \mathrm{PG}$ Second Year, ${ }^{2} \mathrm{PG}$ Third Year, ${ }^{4,5}$ Professor, ${ }^{6} \mathrm{HOD},{ }^{1-6}$ Dept. of Pediatric and Preventive Dentistry, ITS-Centre for Dental Studies \& \\ Research Muradnagar, Ghaziabad, Uttar Pradesh, India \\ *Corresponding Author: Vinita Goyel \\ Email:vgoyel123@gmail.com
}

\begin{abstract}
This article discusses about a fixed dentulous appliance that was constructed to replace the primary upper anterior teeth in a five year old boy. It constituted of a design, where the maxillary primary second molars were used to support the appliance through bands and a wire that contained spurs bearing strip crowns, anteriorly. The appliance was functionally and aesthetically compliant.
\end{abstract}

Keywords: Early childhood caries, Fixed dentulous appliance, Pediatric ridge.

\section{Introduction}

One of the most common condition that we come across in pediatric practice is early childhood caries (ECC). ${ }^{1}$ According to American dental association ECC is defined as the presence of one or more decayed (non cavitated or cavitated lesions), missing (due to caries) or filled tooth surfaces in any primary tooth in a pre-school-age child between birth and 71 months of age. The term "severe early childhood caries" refers to "atypical" or "progressive" or "acute" or "rampant" pattern of dental caries. The main cause of this carious pattern is improper feeding habit, intake of sugary food, frequent snacking, lack of oral hygiene, lack of fluoride exposure and enamel defects are some of the major factors responsible for the development of ECC. ${ }^{2}$ Labial surfaces of all anteriors are the first to degrade on effect of this lesion following rapid diffuse demineralisation to the gross destruction of all anterior primary teeth. ${ }^{3}$

The psychological status of pre-schooler as well as his/her parents get altered due to early loss of primary anterior teeth due to aesthetic appearance. ${ }^{4}$

So, it becomes greatest challenge for any pediatric dentist to rehabilitate the masticatory function, space maintenance, aesthetic appearance via fixed dentulous appliance.

Few articles have been published describing the design of this appliance, ${ }^{5-7}$ but there is a lack of information available with the clinicians for the construction of this appliance using spurs and strip crowns. This paper highlights one type of fixed dentulous appliance for maxillary edentate pediatric ridge using aesthetic crowns and wire.

\section{Case Report}

A 5-year-old boy reported to the Department of Pedodontics and Preventive Dentistry with the chief complaint of missing anterior teeth since 1 month. On taking the history from patient's parents, it was reported that precocious shedding of upper anterior teeth was due to caries and parents accepted their negligence regarding oral health of the child. Now, they were concerned about the aesthetics of the child, and they wanted an aesthetic replacement of the anterior teeth.

Intraoral examination revealed missing 51,52,61,62. (Fig. 1). A clinical decision was made to fabricate a fixed dentulous appliance for replacing the missing anterior teeth.

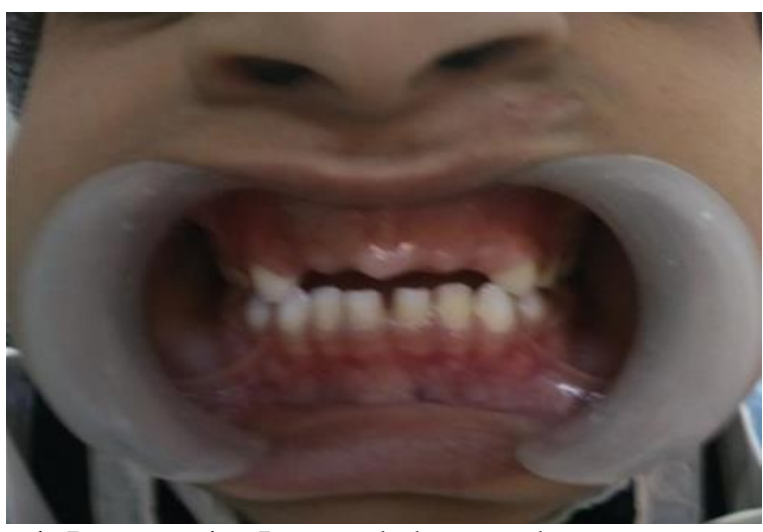

Fig. 1: Pre operative Intra oral photograph.

\section{Appointment Schedule 1st appointment}

As it was the first visit of the patient to the dental clinic, so the patient was quite apprehensive about the surroundings and treatment. That's why in the first visit, patient's behaviour modification was done with the help of desensitization, live modelling, introducing to the department and making him friendly to the clinician and the environment.

\section{2nd appointment}

Treatment was started with Phase 1 therapy i.e. oral prophylaxis. The treatment plan was made. 55,65 were chosen as abutments for the appliance.

\section{3rd appointment}

Banding was done irt 55 \& 65. An impression was made of both the arches with the help of irreversible hydrocolloid material impression material. The patient was sent and was recalled after 3 days. 


\section{Lab work}

The impression was poured with the help of type II dental stone. The $\mathrm{U}$ shaped wire component was fabricated in the cast similar to Nance palatal arch. It was soldered to the bands. A second wire component in the form of spurs of about $4 \mathrm{~mm}$ was soldered on the main archwire. To this assembly, four crowns were built up with the help of strip crowns and light cure composite in relation to 51,52,61,62.(Fig 2.1,2.2,2.3) The final appliance was trimmed, polished and was ready for a trial.

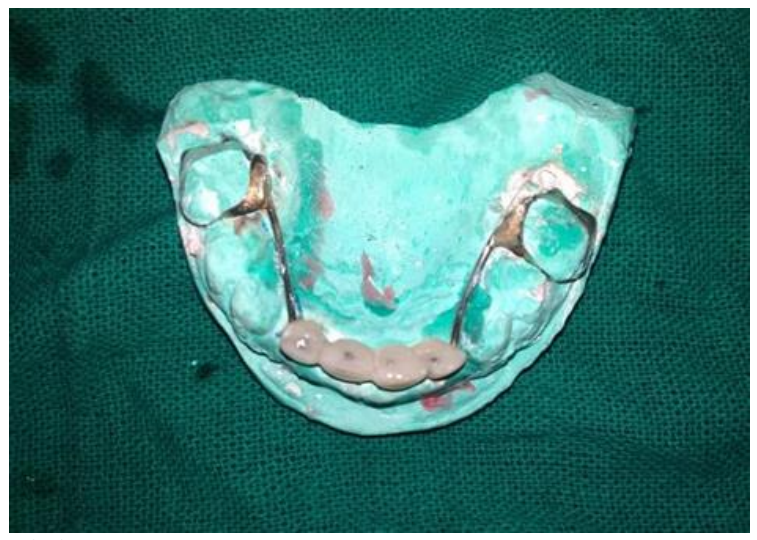

Fig. 2.1: Appliance simulation on cast

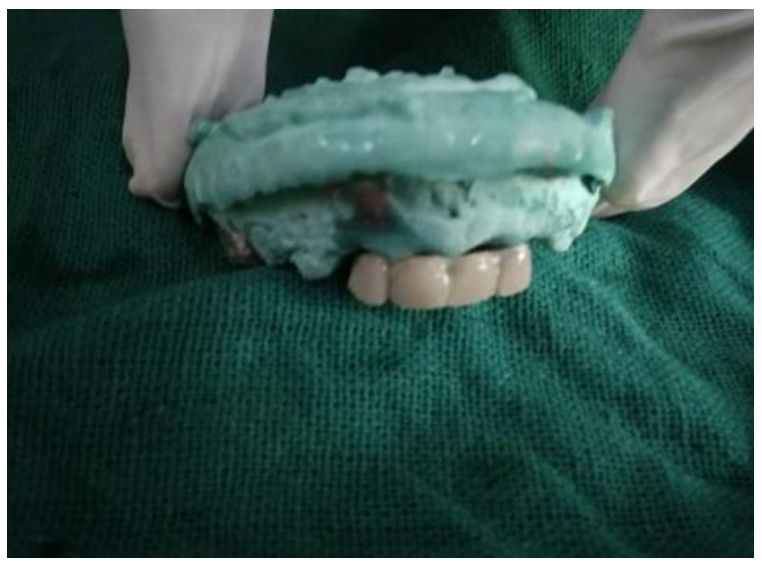

Fig. 2.2: Appliance Modification and confirmation on cast

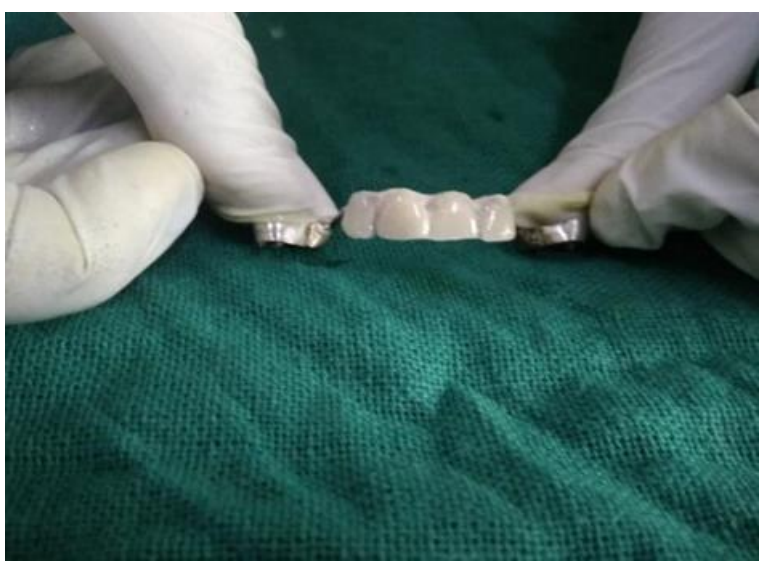

Fig. 2.3: Extra oral photograph of the finished Appliance

\section{4th appointment}

The appliance was tried in the patient's mouth and occlusion was checked. The appliance was then cemented using GIC with the help of bands in relation to 55 and 65.(Fig. 3)The patient was followed up for 3 months.

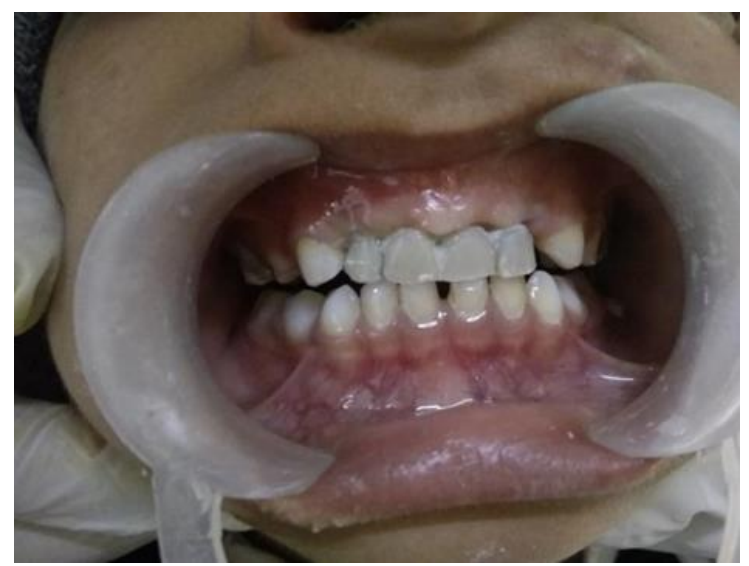

Fig. 3: Intra oral photograph of cemented appliance

In the follow up appointment (Fig. 4), we observed the discolouration of teeth due to resident chromogenic bacteria presents in patient's mouth, and intake of coloured drinks.

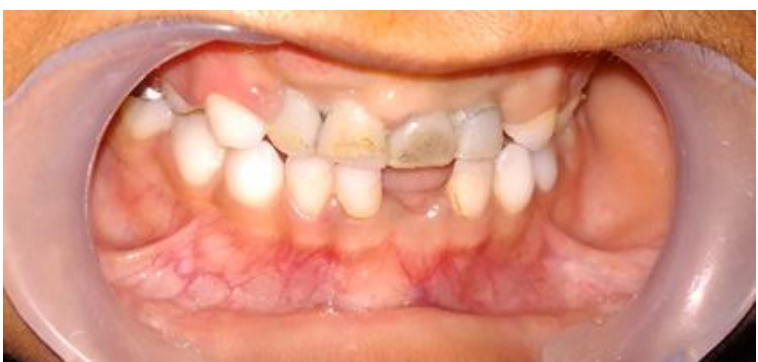

Fig. 4: Follow up Intra oral photograph of cemented appliance

\section{Discussion}

As far as literature is concerned, there is no strong fact quoting the undesirable effects on the growth and development of the child due to the early loss of primary anterior teeth. It totally depends on the patient's desire for the replacement of anterior teeth with the aesthetic appliance. ${ }^{8}$

In 1985, Rickman and El Badravy ${ }^{9}$ reported that 4 out of 14 children who prematurely lost maxillary primary incisors due to ECC has some degree of impairment with 2 being severe.

The outcomes of premature loss of primary anterior teeth can affect one's self-image and thus affecting the quality of life. However, literature also suggests that preschool children attribute behavioral characteristics to other children based on their attractive and unattractive appearance. ${ }^{10}$

When taking all the factors into consideration if the parents want the replacement of missing anterior teeth, then that should not be discouraged. ${ }^{11}$ This space maintainer 
offer several advantages in terms of aesthetics, restoration of speech and mastication, and preventing non-nutritive oral habit development

However, the primary advantage is that there is no food accumulation and plaque because of strip crowns.

Knowledge is still at infancy among pediatric dentists for using strip crowns and wire bending as a new combination for anterior esthetic rehabilitation among pediatric patients, So this paper offered an example of new treatment modality.

\section{Conclusion}

Child gets mentally traumatized on losing anterior teeth. So, this appliance gave a huge psychological boost for the child and his parents. It also acts as functional space maintainers, assist in development of proper speech; prevent development of any untoward oral habits thus aiding sound development for the child during the foundation years.

\section{Source of funding}

None.

\section{Conflict of interest}

None.

\section{References}

1. Harris R, Nicoll AD, Adair PM, Pine CM. Risk factors for dental caries in young children: a systematic review of the literature. Community Dent Health 2004;21(1):71-85.

2. Uribe S. Early childhood caries - risk factors. Evid Based Dent 2009;10(2):37-8.

3. Milgrom P, Riedy CA, Weinstein P, Tanner AC, Manibusan L, Bruss J. Dental caries and its relationship to bacterial infection, hypoplasia, diet, and oral hygiene in 6- to 36-month-old children. Community Dent Oral Epidemiol 2000;28(4):295-9.

4. Steffen JM, Miller JB, Johnson R. An esthetic method of anterior space maintenance. J Dent Child 1971;38(3):154-7.

5. Klapper BJ, Strizak-Sherwin R. Esthetic anterior space maintenance. Ped Dent 1983; 5(2):121-3.

6. Jasmin JR, Groper JN. Fabrication of a more durable fixed anterior esthetic appliance. J Dent Child 1984;51(2):124-7.

7. Waggoner WF, Kupietzky A. Anterior esthetic fixed appliances for the preschooler: Considerations and a technique for placement. Pediatr Dent 2001;23:147-50.

8. Hawes R. Traumatized primary anterior teeth. Dent Clin North Am 1966;10:391-404.

9. Riekman GA, el Badrawy HE. Effect of premature loss of primary maxillary incisors on speech. Pediatr Dent 1985;7:119-22.

10. Giannetti L, Murri A, Vecci F, Gatto R. Dental avulsion: therapeutic protocols and oral health related quality of life. Eur J Paediatr Dent 2007;8:69-75.

11. Langlois JH, Stephan C. The effects of physical attractiveness and ethnicity on children's behavioral attributions and peer preferences. Child Develop 1977;48:1694-8.

How to cite this article: Goyel V, Wilson I, Jain A, Mathur S, Chopra R, Sachdev V. Fixed dentulous appliance for maxillary edentate pediatric ridge: A case report. J Dent Specialities 2019;7(2):132-4. 